\title{
Porous carbons from hydrothermal carbonization of corn stover for highly efficient $\mathrm{CO}_{2}$ capture
}

\author{
Xinhua Qi ${ }^{a,}{ }^{*}$, Yu Wang ${ }^{b}$ and Feng Shen ${ }^{c}$ \\ Agro-Environmental Protection Institute, Chinese Academy of Agricultural Sciences, No. 31, \\ Fukang Road, Nankai District, Tianjin 300191, China \\ aqixinhua@aepi.org.cn, b258747447@qq.com, shenfeng@aepi.org.cn
}

\begin{abstract}
Keywords: Corn stover; Activated carbon; $\mathrm{CO}_{2}$ capture; Hydrothermal carbonization; Agricultural waste; Biomass

Abstract. Sustainable biomass-derived carbon materials were produced by hydrothermal carbonization of corn stover that was followed by chemical activation with $\mathrm{KOH}$. The prepared carbon materials were used for $\mathrm{CO}_{2}$ adsorption, and had a $\mathrm{CO}_{2}$ uptake of $7.14 \mathrm{mmol} / \mathrm{g}$ at a pressure of $1 \mathrm{bar}$ and at $0{ }^{\circ} \mathrm{C}$ that was much higher than $\mathrm{CO}_{2}$ uptake by activated carbon that was prepared from direct activation of corn stover $(2.78 \mathrm{mmol} / \mathrm{g})$. The porous corn stover-derived carbonaceous material had high surface area $\left(2442 \mathrm{~m}^{2} / \mathrm{g}\right)$ and large pore volume $\left(1.55 \mathrm{~cm}^{3} / \mathrm{g}\right)$. Product yields obtained by activation of hydrothermally carbonized corn stover were significantly higher than that by the direct activation of corn stover (36-75\% VS. 8\%). The prepared corn stover-derived porous carbon had a high $\mathrm{CO}_{2} / \mathrm{N}_{2}$ selectivity of 15.5 , and exhibited constant $\mathrm{CO}_{2}$ uptake for five successive reuse cycles. The hydrothermal carbonization step plays important role for producing porous carbons from biomass that have high and specific adsorption properties.
\end{abstract}

\section{Introduction}

Carbon capture will become a vital technology in the near-future as society shifts from carbon-based energy to carbon-free energies. Great efforts have been made to exploit $\mathrm{CO}_{2}$ capture and storage processes that rely on absorption [1], adsorption [2] or membrane separation [3]. The absorption of $\mathrm{CO}_{2}$ with alkano-amine solvents is presently the most widely used method for $\mathrm{CO}_{2}$ capture $_{[4]}$, however, it has problematic issues related to equipment corrosion, energy consumption and solvent toxicity. Adsorption of $\mathrm{CO}_{2}$ using solid adsorbents is a promising alternative for $\mathrm{CO}_{2}$ capture, since there are many adsorbents that can be used such as porous carbons [5, 6], zeolites [7] and metal organic frameworks $[8,9]$. Among the many types of adsorbents, porous carbons for $\mathrm{CO}_{2}$ capture are advantageous because they are robust, they have high specific surface area, variable pore structure, hydrophobicity, low energy consumption for regeneration and they are safe and nontoxic.

Numerous kinds of precursors such as coal, petroleum coke, and charcoal, have been applied to prepare porous carbons. Compared with these conventional precursors, biomass is a more suitable feedstock in terms of cost, availability and its renewability $[10,11]$.Various biomass feedstocks such as coconut shells [12], peanut shells [13], bamboo [2], and empty fruit brunch [14] have been applied as carbon precursors to produce porous carbons for $\mathrm{CO}_{2}$ sorption, by either direct chemical activation with $\mathrm{KOH}$ or by physical activation with $\mathrm{CO}_{2}$ as the activation agent. However, these methods have some disadvantages such as waste stream emission and low carbon yield. On the other hand, hydrothermal carbonization adopted for pre-carbonization of biomass following with $\mathrm{KOH}$ activation allows efficient preparation of porous carbons $[15,16]$. For example, Sevilla et al. used glucose as raw material and prepared activated carbon by hydrothermal treatment and $\mathrm{KOH}$ post-treatment to obtain materials for electrodes supercapacitors [17].

Corn stover is a widely distributed agricultural waste that mainly consists of organic cellulose, hemicellulose, lignin and inorganics [18], and as an underused by-product, it is a promising precursor to produce porous carbon at low cost. In this work, corn stovers were treated under hydrothermal conditions and post-treated with $\mathrm{KOH}$ for activation. The obtained corn stover-derived porous carbons had high microporosity and had favorable $\mathrm{CO}_{2}$ adsorption characteristics. The objectives of 
this research were to evaluate conditions for preparing corn stover porous carbons and to assess the materials for $\mathrm{CO}_{2}$ capture and regeneration. Evaluation of the selectivity of the materials for $\mathrm{CO}_{2} / \mathrm{N}_{2}$ gas mixture was also studied, since $\mathrm{CO}_{2}$ often has to be removed from gas streams that contain air.

\section{Methods}

Materials. Corn stover (CS) material was collected from a local farm in Tianjin, China. Samples were crushed to pass a 180 mesh sieve and sun-dried before use. Potassium hydroxide (analytic grade) and ethanol (analytic grade) were provided by Guangfu fine chemicals research institute (Tianjin, China).

Preparation of corn stover-derived porous carbon. The corn stover-derived porous carbon was prepared in two steps. First, hydrothermal treatment was applied to give hydrochar material (HC). Raw corn stover (12 g) was dispersed in $60 \mathrm{~mL}$ water and was loaded into a Telfon-lined stainless steel autoclave $(100 \mathrm{~mL})$, and hydrothermally treated at $250{ }^{\circ} \mathrm{C}$ for $10 \mathrm{~h}$ at the autogenous pressure. After the reaction, the autoclave was cooled with ice water rapidly within several minutes. The resulting solid product was separated with centrifuge and was subjected to washing several times with ultrapure water and ethanol. The washed solids were dried in an oven at $80{ }^{\circ} \mathrm{C}$.

Second, the as-prepared $\mathrm{HC}$ material was chemically activated with $\mathrm{KOH}$ by thoroughly mixing the $\mathrm{HC}$ material with $\mathrm{KOH}$ at a given mass ratio $(\mathrm{KOH}: \mathrm{HC}=1: 1-4: 1)$, and heated in a horizontal tubular furnace (OTF-1200X, Hefei Kejing Materials Technology Co. LTD) to the target temperature (600 to $900{ }^{\circ} \mathrm{C}$ ) under a nitrogen gas flow atmosphere for $1-4 \mathrm{~h}$. The resulting solid material was washed with $1 \mathrm{M} \mathrm{HCl}$ solution and ultra-pure water several times until the filtrate became neutral in $\mathrm{pH}$, and then the obtained wet solid was dried at $80{ }^{\circ} \mathrm{C}$ overnight. The final obtained corn stover-derived porous carbons were denoted as $\mathrm{AC} x-y-z$, where $x, y$ and $z$ represents the activation temperature $\left({ }^{\circ} \mathrm{C}\right)$, the weight ratio of $\mathrm{KOH} / \mathrm{HC}$ and the activation time $(\mathrm{h})$, respectively.

Direct activation of corn stover consists of the above steps without hydrothermal carbonization. Corn stover was directly mixed with $\mathrm{KOH}$ at a mass ratio of 2:1 (KOH:CS) and heated under a nitrogen gas flow atmosphere at $800{ }^{\circ} \mathrm{C}$ for $2 \mathrm{~h}$, and the activated carbon obtained $\left(\mathrm{CS}_{800-2-2}\right)$.

Characterization. The surface morphology of the corn stover-derived porous carbon was characterized with scanning electron microscopy (SEM) using a HITACHI S4800 microscope. Nitrogen sorption isotherms of the AC materials were measured at $-196^{\circ} \mathrm{C}$ using a 3FLEX apparatus (Micromeritics Instrument Corp., USA) and analyses were made to characterize the surface properties and pore sizes. Prior to the measurements, each sample was degassed under vacuum at $200{ }^{\circ} \mathrm{C}$ for $5 \mathrm{~h}$. Elemental analysis (CHN) was conducted on a dry basis using elemental analyzer (Elementar Analysensysteme GmbH, Germany).

$\mathrm{CO}_{2}$ adsorption-desorption experiments. $\mathrm{CO}_{2}$ adsorption-desorption experiments were carried out at 0.01 to 1 bar using static gas adsorption (3FLEX apparatus, Micromeritics Instrument Corp., USA) at $0{ }^{\circ} \mathrm{C}$. Selectivity of the prepared porous carbon for the gases was evaluated by the ratio of adsorbed amounts of $\mathrm{CO}_{2}$ and $\mathrm{N}_{2}$ on a molar basis at equilibrium at $0{ }^{\circ} \mathrm{C}$ and 1 bar. After adsorption equilibrium was achieved, The porous carbons were regenerated at $0{ }^{\circ} \mathrm{C}$ under vacuum $(<0.01$ bar $)$. A second adsorption was repeated at $0{ }^{\circ} \mathrm{C}$ and 1 bar after regeneration. Five $\mathrm{CO}_{2}$ adsorption-desorption cycles were performed for the most favorable corn stover-derived porous carbon among those prepared $\left(\mathrm{AC}_{800-2-2}\right)$ to confirm regeneration and recycle characteristics.

\section{Results and discussion}

Textural properties of the porous carbons. Variation in the morphology of the corn stover porous carbons before and after hydrothermal carbonization and chemical activation was observed by means of scanning electron microscopy (SEM) (Figure 1). The crude corn stovers were mainly composed of rod-shaped fibers (Figure 1a), while the SEM images of the HC samples obtained from hydrothermal carbonization of the corn stovers showed the presence of carbonaceous microspheres that were probably derived from the saccharide components in the corn stovers along with presence of irregular 
components (Figure 1b). The HC samples had a brown color that is typical for incomplete hydrothermal carbonization products of biomass [17]. After the HC samples were chemically activated with $\mathrm{KOH}$, the original morphology of the hydrochar materials were completely destroyed, and were transformed into honeycomb-like structures with large conchoidal cavities. The activation of the HC by $\mathrm{KOH}$ typically causes morphology changes such as those observed in Figure 1c [19]. For the $\mathrm{CS}_{800-2-2}$ sample that was prepared from the direct activation of corn stover with $\mathrm{KOH}$ at $800{ }^{\circ} \mathrm{C}$ for $2 \mathrm{~h}$, the material was composed of relatively small particles with irregular morphology (Figure 1d).

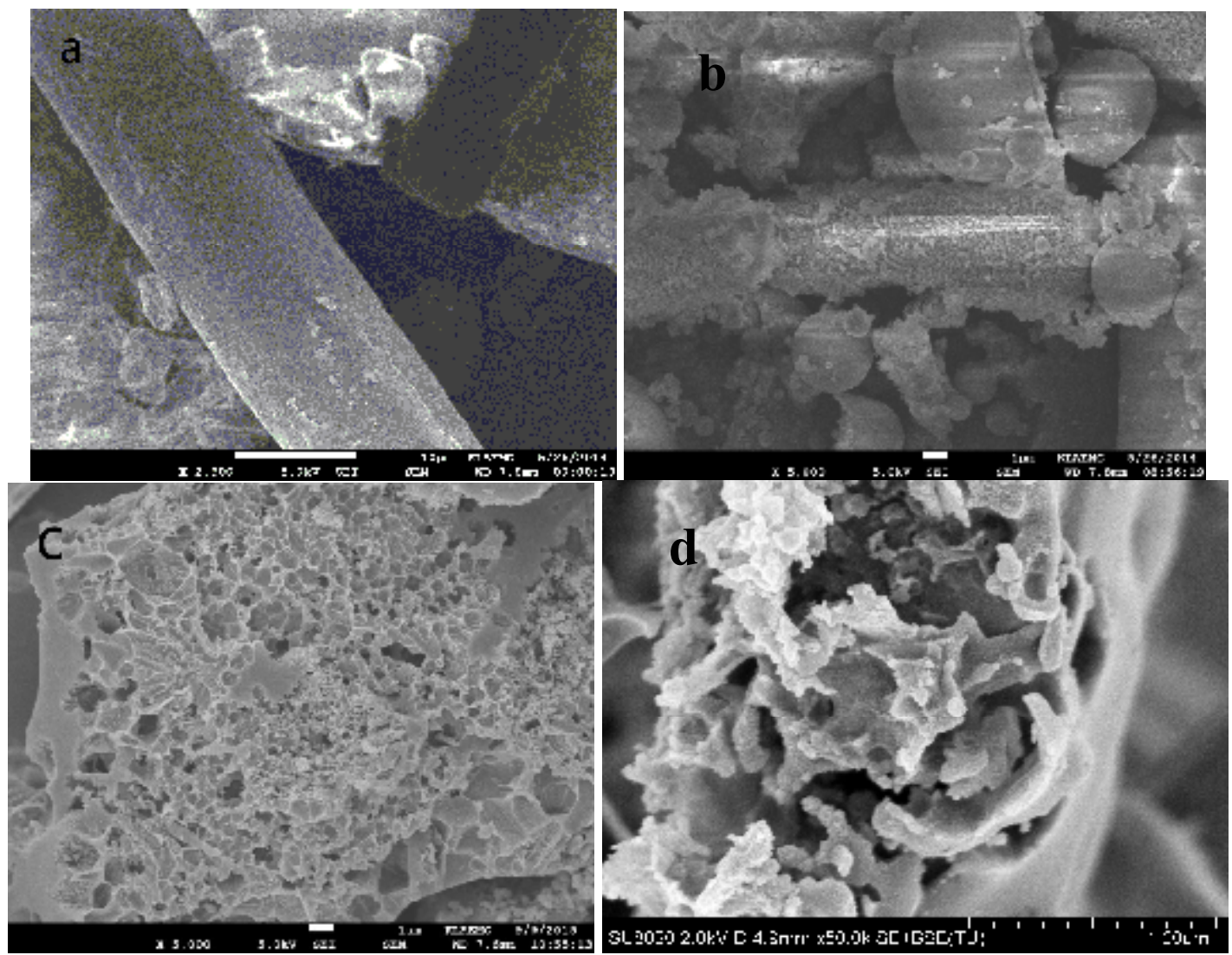

Figure 1. SEM images of the (a) raw corn stovers, (b) hydrothermal treated hydrochar material (HC), (c) Hydrothermal treated $\mathrm{KOH}$ activated porous carbon $\mathrm{AC}_{800-2-2}$ and (d) direct activated (non-hydrothermal treated) porous carbon $\mathrm{CS}_{800-2-2}$.

The structural characteristics of the prepared carbon materials under various conditions were investigated by means of $\mathrm{N}_{2}$ physisorption and the results are shown in Table 1, where it is apparent that all activation parameters, such as temperature, $\mathrm{KOH} / \mathrm{HC}$ ratio and activation time affected the properties of the prepared porous carbonaceous materials. The highest BET surface area sample was for $\mathrm{AC}_{800-2-2}\left(2442 \mathrm{~m}^{2} / \mathrm{g}\right)$ that also had the highest total pore volume $\left(1.56 \mathrm{~cm}^{3} / \mathrm{g}\right)$. For the corn stover derived porous carbon materials (Table 1 ), $800^{\circ} \mathrm{C}, \mathrm{KOH} / \mathrm{HC}$ ratio of 2 and activation time of $2 \mathrm{~h}$ were found to be the optimum activation conditions among those examined in terms of surface area and pore volume. With the increase of activation temperature, $\mathrm{KOH}$ dosage or activation time, the specific surface area of the materials began to decrease along with the enlargement of existing pores. The surface area of $\mathrm{AC}_{800-2-2}$ prepared by activation of hydrothermal treated corn stover was much higher than $\mathrm{CS}_{800-2-2}$ which was prepared by direct activation of corn stover without hydrothermal treatment. The hydrothermal carbonization pretreatment of corn stover probably has a homogenizing effect, which removes undesirable mineral matter from the carbonaceous material [20]. 
Table 1. Structural characteristics, properties, elemental composition, $\mathrm{CO}_{2}$ uptake, and product yield of activated carbons derived from corn stover according to preparation conditions of activation temperature, weight ratio of $\mathrm{KOH}$ to hydrochar ( $\mathrm{KOH}: \mathrm{HC})$ and activation time.

\begin{tabular}{|c|c|c|c|c|c|c|c|c|c|c|c|c|c|}
\hline Sample & $\begin{array}{l}\text { Temp } \\
\left({ }^{\circ} \mathrm{C}\right)\end{array}$ & $\underset{\text { ratio }}{\mathrm{KOH} / \mathrm{HC}}$ & $\begin{array}{l}\text { Activation } \\
\text { time (h) }\end{array}$ & $\begin{array}{c}\mathrm{S}_{\mathrm{BEE}} \mathrm{a}^{\mathrm{a}} \\
\left(\mathrm{m}^{2} / \mathrm{g}\right)\end{array}$ & $\begin{array}{c}\mathrm{S}_{\text {micro }} \\
\left(\mathrm{m}^{2} / \mathrm{g}\right)\end{array}$ & $\begin{array}{c}\mathrm{V}_{\mathrm{t}}^{\mathrm{b}} \\
\left(\mathrm{cm}^{3} / \mathrm{g}\right)\end{array}$ & $\begin{array}{c}\mathrm{V}_{0} \mathrm{c} \\
\left(\mathrm{cm}^{3} / \mathrm{g}\right)\end{array}$ & $\begin{array}{l}V_{<0,7 \mathrm{~mm}} \\
\left(\mathrm{~cm}^{3 / g} / \mathrm{g}\right)\end{array}$ & $\begin{array}{l}\mathrm{C} \\
(\%)\end{array}$ & $\mathrm{N}(\%)$ & $\mathrm{H}($ & $\begin{array}{c}\mathrm{CO}_{2} \\
\text { uptake } \\
(\mathrm{mmol} / \mathrm{g})\end{array}$ & $\begin{array}{l}\text { Product } \\
\text { yield (\%) }\end{array}$ \\
\hline $\mathrm{HC}$ & - & - & - & 11 & - & 0.04 & - & - & 43.40 & 0.48 & 6.22 & 0.71 & 88 \\
\hline $\mathrm{AC}_{600-2-2}$ & 600 & 2 & 2 & 955 & 788 & 0.43 & 0.31 & 0.24 & 57.46 & 0.66 & 3.37 & 4.93 & 75 \\
\hline $\mathrm{AC}_{700-2-2}$ & 700 & 2 & 2 & 1539 & 1232 & 0.72 & 0.48 & 0.35 & 59.20 & 0.34 & 3.70 & 6.80 & 55 \\
\hline $\mathrm{AC}_{800-2-2}$ & 800 & 2 & 2 & 2442 & 2149 & 1.56 & 0.86 & 0.48 & 60.41 & 0.24 & 3.91 & 7.14 & 54 \\
\hline $\mathrm{AC}_{900-2-2}$ & 900 & 1 & 2 & 2225 & 1199 & 1.11 & 0.49 & 0.35 & 64.91 & 0.24 & 3.12 & 5.79 & 36 \\
\hline $\mathrm{AC}_{800-1-2}$ & 800 & 4 & 2 & 1543 & 1439 & 0.71 & 0.61 & 0.32 & 66.56 & 0.86 & 2.99 & 5.06 & 58 \\
\hline $\mathrm{AC}_{800-42}$ & 800 & 2 & 2 & 2170 & 1983 & 1.27 & 0.66 & 0.22 & 54.94 & 0.32 & 2.19 & 4.86 & 41 \\
\hline $\mathrm{AC}_{800-2-1}$ & 800 & 2 & 1 & 1630 & 1553 & 0.69 & 0.60 & 0.38 & 76.91 & 0.20 & 2.73 & 6.47 & 56 \\
\hline $\mathrm{AC}_{800-24}$ & 800 & 2 & 4 & 1862 & 1753 & 0.81 & 0.69 & 0.38 & 58.22 & 0.22 & 3.79 & 6.32 & 50 \\
\hline $\mathrm{CS}_{800-2-2}$ & 800 & 2 & 2 & 904 & 650 & 0.45 & 0.26 & 0.15 & 44.39 & 0.10 & 2.67 & 2.78 & 8 \\
\hline
\end{tabular}

${ }^{a}$ Surface area was calculated using the Brunauer-Emmett-Teller method at $\mathrm{P} / \mathrm{P}_{0}=0.01-0.1 .{ }^{\mathrm{b}}$ Total pore volume at $\mathrm{P} / \mathrm{P}_{0}=0.99$. 'Total micropore volume was calculated from $\mathrm{N}_{2}$ adsorption data by t-plot method.

$\mathrm{CO}_{2}$ capture capacity. The preparation conditions shown in Table 1 had a large effect on the properties of the porous carbons and thus the $\mathrm{CO}_{2}$ adsorption capacities should be different. To determine appropriate preparation parameters of the corn stover-derived porous carbons for $\mathrm{CO}_{2}$ adsorption, experiments using the three parameters (activation temperature, precursor $/ \mathrm{KOH}$ ratio and activation time) were conducted (Figure 2 and Table 1). It shows that the activation temperature and $\mathrm{KOH} / \mathrm{HC}$ ratio had a large effect on the $\mathrm{CO}_{2}$ uptake onto the corn stover-derived activated carbons, while the activation time did not affect the adsorbed amounts much.

As shown in Figure 2a, when the $\mathrm{KOH} / \mathrm{HC}$ ratio and activation time were fixed at 2 and $2 \mathrm{~h}$, respectively, the amount of $\mathrm{CO}_{2}$ adsorbed on the porous carbons first increased with an increase in activation temperature from 600 to $800{ }^{\circ} \mathrm{C}$, and then decreased at $900{ }^{\circ} \mathrm{C}$. The maximum $\mathrm{CO}_{2}$ uptake at $0{ }^{\circ} \mathrm{C}$ was $7.14 \mathrm{mmol} / \mathrm{g}$ (Table 1 ) was achieved for $\mathrm{AC}_{800-2-2}$ sample that was $\mathrm{KOH}$-activated at $800{ }^{\circ} \mathrm{C}$. The high adsorption capacity of $\mathrm{AC}_{800-2-2}$ for $\mathrm{CO}_{2}$ is ascribed to its high surface area, high total volume and micropore volume. It has been reported that micropores, especially narrow micropores less than $0.7 \mathrm{~nm}$, play an important role in enhancing $\mathrm{CO}_{2}$ adsorption [21]. Moreover, the presence of heteroatoms, such as nitrogen, influences the $\mathrm{CO}_{2}$ adsorption performance $[22,23]$. When the relationship between the structural properties and surface functional groups and $\mathrm{CO}_{2}$ adsorption was explored, it was found that not only the BET surface area and total pore volume affect the $\mathrm{CO}_{2}$ uptake, but also the narrow micropore volume and nitrogen content (Table 1) are important. Among the four samples prepared at different temperatures, $\mathrm{AC}_{700-2-2}$, which had a comparable micropore surface area, total micropore volume and narrow micropore volume as that of $\mathrm{AC}_{900-2-2}$, exhibited higher $\mathrm{CO}_{2}$ adsorption capacity than $\mathrm{AC}_{900-2-2}$, which can be ascribed to the higher nitrogen content of $\mathrm{AC}_{700-2-2}$ over that of $\mathrm{AC}_{900-2-2}$ (Table 1). Although both $\mathrm{AC}_{800-2-2}$ and $\mathrm{AC}_{900-2-2}$ had the same nitrogen content and similar surface area (Table 1), $\mathrm{AC}_{800-2-2}$ exhibited the highest $\mathrm{CO}_{2}$ capture capacity, because its high micropore volume and narrow micropore volume. On the other hand, although $\mathrm{AC}_{600-2-2}$ had the highest nitrogen content among the four samples, its least developed porosity probably lead to its low $\mathrm{CO}_{2}$ capture capacity. Thus, both physical and chemical properties seem to control $\mathrm{CO}_{2}$ adsorption. When the microporous structure is filled by $\mathrm{CO}_{2}$, van der Waals interactions influence the adsorption, while the presence of functional groups allows chemisorption to occur, which is also one of the important factors that affects $\mathrm{CO}_{2}$ adsorption [24].

Figure $2 \mathrm{~b}$ shows the influence of the activation agent amount on the prepared porous carbons on $\mathrm{CO}_{2}$ adsorption. For an activation temperature and time of $800{ }^{\circ} \mathrm{C}$ and $2 \mathrm{~h}$, respectively, the adsorption of porous carbons for $\mathrm{CO}_{2}$ first increased but then declined with an increase in applied $\mathrm{KOH}$ amount. A 2:1 KOH:HC ratio was found to give the highest $\mathrm{CO}_{2}$ uptake amount for the range of $\mathrm{KOH}: \mathrm{HC}$ ratios 
examined. Sevilla and Yang et al. reported that activated carbon prepared from at a $\mathrm{KOH}$ : $\mathrm{HC}$ ratio of 2 exhibited better adsorption capacity than the other ratios $[12,25]$. Although $\mathrm{AC}_{800-1-2}$ had a lower BET surface area, total pore volume and even micropore volume than $\mathrm{AC}_{800-4-2}$, its capacity for $\mathrm{CO}_{2}$ adsorption was higher (Table 1), which can probably be explained by its higher $\mathrm{N}$ content and narrow micropore volume of less than $0.7 \mathrm{~nm}$ (Table 1).

The influence of activation time on $\mathrm{CO}_{2}$ adsorption was studied for an activation temperature of $800^{\circ} \mathrm{C}$ and a $\mathrm{KOH} / \mathrm{HC}$ ratio of 2 . Compared with activation temperature and $\mathrm{KOH} / \mathrm{HC}$ ratio, the effect of activation time on $\mathrm{CO}_{2}$ adsorption capacity was not strong (Figure 2c). When the $\mathrm{HC}$ sample was chemically activated for $1 \mathrm{~h}$, the obtained $\mathrm{AC}_{800-2-1}$ sample exhibited a $\mathrm{CO}_{2}$ uptake of $6.47 \mathrm{mmol} / \mathrm{g}$. After the activation time was extended to $2 \mathrm{~h}$, the porous structure of the carbonaceous material was thoroughly developed to afford a high specific surface area, total pore and micropore volume (Table 1), which allowed the $\mathrm{AC}_{800-2-2}$ sample to have the highest $\mathrm{CO}_{2}$ uptake among the materials. By prolonging the activation time to $4 \mathrm{~h}$, the surface area and micropore volume of the obtained $\mathrm{AC}_{800-2-4}$ sample began to decrease, and its adsorption capacity for $\mathrm{CO}_{2}$ decreased to a comparable value as that for the $\mathrm{AC}_{800-2-1}$ sample.
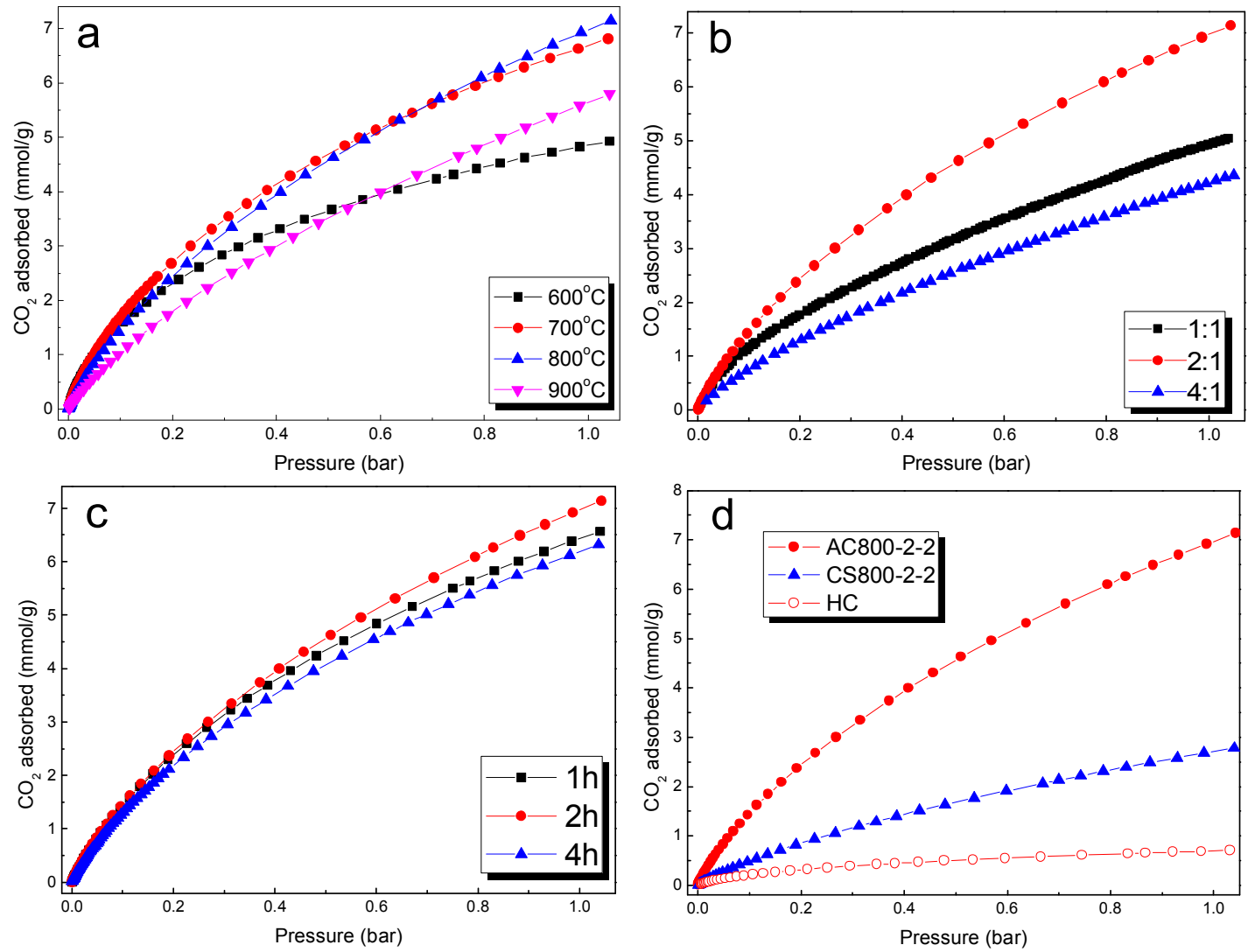

Figure 2. Comparison of $\mathrm{CO}_{2}$ adsorption isotherms at $0{ }^{\circ} \mathrm{C}$ for (a) corn stover-derived activated carbons prepared at different activation temperatures, (b) $\mathrm{KOH} /$ precursor ratio, (c) activation time and (d) those among $\mathrm{HC}, \mathrm{AC}_{800-2-2}$ and $\mathrm{CS}_{800-2-2}$ samples.

The yields of the obtained carbon material products (Table 1) were different among the ACs and CS samples. Product yields of 36-75\% could be obtained for carbon materials produced from hydrothermal carbonization of corn stover following with $\mathrm{KOH}$ activation, which is significantly higher compared with that for the direct activation sample $\left(\mathrm{CS}_{800-2-2}\right)$. Deoxygenation occurs in hydrothermal carbonization to form more highly-aromatic structures [17], so this is probably the reason that the hydrothermally treated corn stover materials had the highest yields (Table 1). Therefore, hydrothermal carbonization of biomass prior to chemical activation is very important for obtaining high yields of porous carbons. 
The hydrothermal carbonization product of corn stover $(\mathrm{HC})$ without $\mathrm{KOH}$ activation showed a $\mathrm{CO}_{2}$ uptake that was significantly lower than that of ACs samples with $\mathrm{KOH}$ activation, indicating that the activation processes could greatly enhance the $\mathrm{CO}_{2}$ uptake. Thus, $\mathrm{KOH}$ activation of hydrochar obtained by hydrothermal carbonization of corn stovers can prepare microporous carbons and can significantly increase the adsorption capacity for $\mathrm{CO}_{2}$. Moreover, as shown in Figure $2 \mathrm{~d}$, the hydrothermal treated and activated sample $\left(\mathrm{AC}_{800-2-2}\right)$ had much greater $\mathrm{CO}_{2}$ uptake than the direct activated material $\left(\mathrm{CS}_{800-2-2}\right)$ (Table 1), which should be ascribed to the greater surface area, larger micropore volume, and higher nitrogen content of $\mathrm{AC}_{800-2-2}$ compared with that of $\mathrm{CS}_{800-2-2}$.

Many researchers have reported on the adsorption of $\mathrm{CO}_{2}$ for different activated carbons and other materials, as shown in Table 2. The porous carbons reported in this study showed higher $\mathrm{CO}_{2}$ uptakes than those reported for other biomass-derived carbons (Table 2). As corn stover is a cheap, abundant and renewable material, corn stover-derived activated carbon from the hydrothermal treating of corn stover followed by $\mathrm{KOH}$ activation is promising for applications in the field of $\mathrm{CO}_{2}$ adsorption.

Table 2. $\mathrm{CO}_{2}$ uptake $\left(0^{\circ} \mathrm{C}\right.$ and 1 bar $)$ for different biomass-derived adsorbents and materials

\begin{tabular}{lcc}
\hline \multicolumn{1}{c}{ Materials } & $\begin{array}{c}\mathrm{CO}_{2} \\
\text { uptake } \\
(\mathrm{mmol} / \mathrm{g})\end{array}$ & Reference \\
\hline Corn stover derived activated carbon $\left(\mathrm{AC}_{800-2-2}\right)$ & 7.14 & This study \\
Nanoporous nitrogen-doped sorbent (UC-650-3) & 6.75 & {$[26]$} \\
Rice husk derived porous carbon (PC3-780) & 6.24 & {$[27]$} \\
Coconut shell derived activated carbon & 5.60 & {$[28]$} \\
Benzimidazole linked polymer (BILP-4) & 5.34 & {$[29]$} \\
Palm fruit bunch derived microporous carbons (H250-800) & 5.23 & {$[14]$} \\
Enteromorpha prolifera based carbon & 2.40 & {$[30]$} \\
Physically activated carbons (PAC) & 1.45 & {$[31]$} \\
Amino-functionalized mesoporous alumina (PA-TEPA) & 1.35 & {$[32]$} \\
\hline
\end{tabular}

Adsorption selectivity and sorbent regeneration. For practical capture of $\mathrm{CO}_{2}$, the adsorbent should have several characteristics, such as large $\mathrm{CO}_{2}$ adsorption capacity, robustness and good selectivity against $\mathrm{N}_{2}$ molecules usually present in flue gas streams. The $\mathrm{CO}_{2} / \mathrm{N}_{2}$ selectivity was examined by determining the adsorption isotherms of $\mathrm{CO}_{2}$ and $\mathrm{N}_{2}$ for $\mathrm{AC}_{800-2-2}$ under the conditions of $0{ }^{\circ} \mathrm{C}$ and 1 bar pressure as shown in Figure 3. According to Figure 3, the adsorption isotherm of $\mathrm{N}_{2}$ was much lower than that of $\mathrm{CO}_{2}$. According to the isotherms and the uptake ratio of $\mathrm{CO}_{2}$ to $\mathrm{N}_{2}$ at adsorption equilibrium, the apparent $\mathrm{CO}_{2} / \mathrm{N}_{2}$ selectivity at a pressure of 1 bar and at $0{ }^{\circ} \mathrm{C}$ for $\mathrm{AC}_{800-2-2}$ was calculated to be 15.5 . This selectivity was higher than those porous carbons prepared from petroleum pitch [33], sawdust [25] and bamboo [2], indicating that the prepared corn stover-derived porous carbon can be used to separate $\mathrm{CO}_{2}$ from $\mathrm{N}_{2}$ efficiently. 


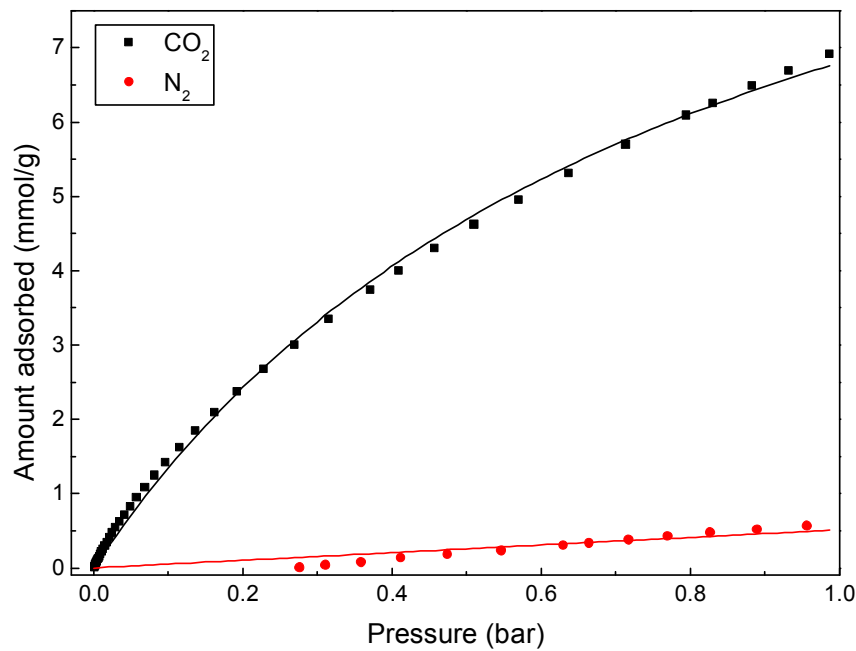

Figure 3. Adsorption isotherms of $\mathrm{CO}_{2}$ and $\mathrm{N}_{2}$ at $0{ }^{\circ} \mathrm{C}$ for $\mathrm{AC}_{800-2-2}$

Regeneration of spent adsorbents is another significant factor in practical application for the adsorption of $\mathrm{CO}_{2}$. Because the interaction between $\mathrm{CO}_{2}$ and biomass-derived carbonaceous adsorbents is generally weak, the adsorption process needs low amounts of energy and the regeneration step can expected to be relatively easy. The regeneration of the prepared porous carbon adsorbent was tested by means of adsorption $\left(\mathrm{CO}_{2}\right.$ at 1 bar)-desorption (pressure $<0.01$ bar) cycles carried out at $0{ }^{\circ} \mathrm{C}$, as shown in Figure 4. It shows that the adsorption isotherms of $\mathrm{CO}_{2}$ onto the $\mathrm{AC}_{800-2-2}$ decreased about $7 \%$ after five successive reuse cycles with low adsorption loss, implying that the $\mathrm{AC}_{800-2-2}$ structure was highly stable and the $\mathrm{CO}_{2}$ adsorption was reversible. Therefore, the prepared corn stovers-derived porous carbons are good adsorbents for $\mathrm{CO}_{2}$, they provide high $\mathrm{CO}_{2} / \mathrm{N}_{2}$ selectivity and they have good recyclability characteristics.

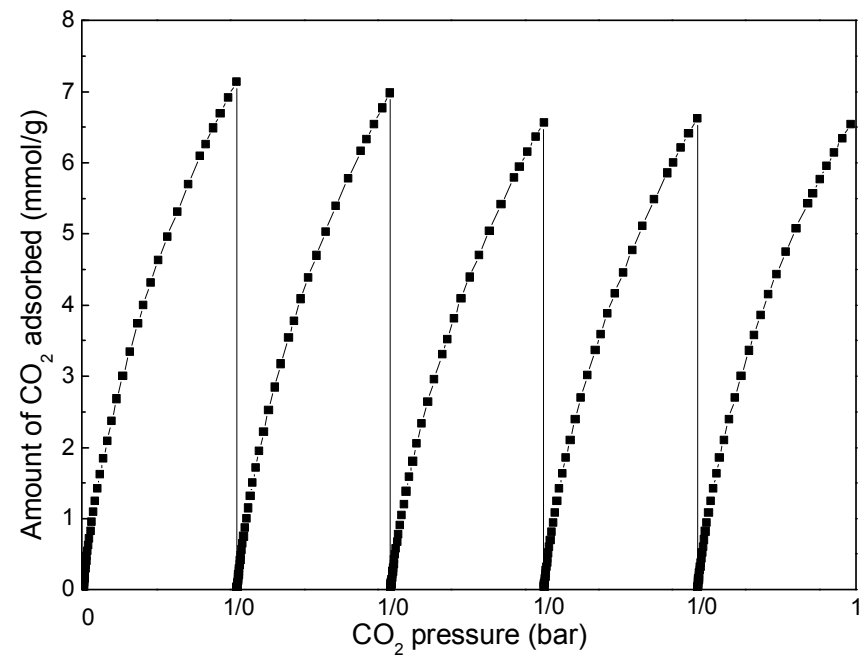

Figure 4. $\mathrm{CO}_{2}$ adsorption on $\mathrm{AC}_{800-2-2}$ at $0{ }^{\circ} \mathrm{C}$ for five cycles with vacuum regeneration.

\section{Conclusions}

Porous carbons were produced from hydrothermal carbonization of corn stover following with $\mathrm{KOH}$ activation, which exhibited much higher $\mathrm{CO}_{2}$ uptake than the activated carbon prepared by the direct activation of corn stover with $\mathrm{KOH}$. Product yields of the prepared materials were significantly higher than those by direct activation of corn stover. The prepared corn stover-derived porous carbon $\mathrm{AC}_{800-2-2}$ had a high $\mathrm{CO}_{2} / \mathrm{N}_{2}$ selectivity of 15.5 and exhibited good recycle characteristics. This work provides a green and promising method to produce high yields of biomass-derived porous carbons from agricultural wastes that have excellent adsorption capacity for $\mathrm{CO}_{2}$ capture. 


\section{Acknowledgements}

The work was partly financially supported from the National Natural Science Foundation of China (No. 21577073). The authors gratefully acknowledge support through The Science and Technology Innovation Program and Elite Youth Program of Chinese Academy of Agricultural Sciences (Dr. Xinhua Qi).

\section{References}

[1] Y.S. Yu, T.T. Zhang, X.M. Wu, D.L. Mu, Z.X. Zhang, G.G.X. Wang, Ind. Eng. Chem. Res. 54 (2015) 6165-6174.

[2] H. Wei, S. Deng, B. Hu, Z. Chen, B. Wang, J. Huang, G. Yu, ChemSusChem 5 (2012) 2354-2360.

[3] S. Park, A.S. Lee, Y.S. Do, S.S. Hwang, Y.M. Lee, J.H. Lee, J.S. Lee, Chem. Commun. 51 (2015) $15308-15311$.

[4] S.Y. Oh, M. Binns, H. Cho, J.K. Kim, Appl. Energy 169 (2016) 353-362.

[5] J.A.A. Gibson, A.V. Gromov, S. Brandani, E.E.B. Campbell, Microporous Mesoporous Mater. 208 (2015) 129-139.

[6] S.-M. Hong, G. Lim, S.H. Kim, J.H. Kim, K.B. Lee, H.C. Ham, Microporous Mesoporous Mater. 219 (2016) 59-65.

[7] Q. Jiang, J. Rentschler, G. Sethia, S. Weinman, R. Perrone, K. Liu, Chem. Eng. J. 230 (2013) 380-388.

[8] Z.H. Rada, H.R. Abid, J. Shang, Y. He, P. Webley, S. Liu, H. Sun, S. Wang, Fuel 160 (2015) 318-327.

[9] H.-Y. Cho, D.-A. Yang, J. Kim, S.-Y. Jeong, W.-S. Ahn, Catal. Today 185 (2012) 35-40.

[10] E. David, J. Kopac, J. Anal. Appl. Pyrolysis 110 (2014) 322-332.

[11] S. Deng, B. Hu, T. Chen, B. Wang, J. Huang, Y. Wang, G. Yu, Adsorption 21 (2015) 125-133.

[12] M. Yang, L. Guo, G. Hu, X. Hu, L. Xu, J. Chen, W. Dai, M. Fan, Environ. Sci. Technol. 49 (2015) 7063-7070.

[13] R.C. Lin, J. Cheng, L.K. Ding, W.L. Song, F. Qi, J.H. Zhou, K.F. Cen, Bioresource Technology 186 (2015) 8-14.

[14] G.K. Parshetti, S. Chowdhury, R. Balasubramanian, Fuel 148 (2015) 246-254.

[15] M. Sevilla, W. Gu, C. Falco, M.M. Titirici, A.B. Fuertes, G. Yushin, J. Power Sources 267 (2014) 26-32.

[16] M.M. Titirici, R.J. White, C. Falco, M. Sevilla, Energy Environ. Sci. 5 (2012) 6796-6822.

[17] M. Sevilla, L. Yu, C.O. Ania, M.-M. Titirici, ChemElectroChem 1 (2014) 2138-2145.

[18] L. Yan, N. Liu, Y. Wang, H. Machida, X. Qi, Bioresour. Technol. 173 (2014) 462-466.

[19] S.L. Chen, G.H. He, X.W. Hu, M.Y. Xie, S.Q. Wang, D.J. Zeng, H.Q. Hou, U. Schroder, ChemSusChem 5 (2012) 1059-1063.

[20] C. Falco, J.P. Marco-Lozar, D. Salinas-Torres, E. Morallon, D. Cazorla-Amoros, M.M. Titirici, D. Lozano-Castello, Carbon 62 (2013) 346-355.

[21] A. Ello, amp, b.S.L.K.C.a.c.A.M. Sergea, Journal of CO2 Utilization 2 (2013) 4.

[22] J.-W. Jeon, L. Zhang, J.L. Lutkenhaus, D.D. Laskar, J.P. Lemmon, D. Choi, M.I. Nandasiri, A. Hashmi, J. Xu, R.K. Motkuri, C.A. Fernandez, J. Liu, M.P. Tucker, P.B. McGrail, B. Yang, S.K. Nune, ChemSusChem 8 (2015) 428-432.

[23] X. Zhang, S. Zhang, H. Yang, Y. Feng, Y. Chen, X. Wang, C. Hanping, Chem. Eng. J. 257 (2014) 8.

[24] A. Arenillas, K.M. Smith, T.C. Drage, C.E. Snape, Fuel 84 (2005) 2204-2210.

[25] M. Sevilla, A.B. Fuertes, Energy Environ. Sci. 4 (2011) 1765-1771.

[26] R. Bai, M. Yang, G. Hu, L. Xu, X. Hu, Z. Li, S. Wang, W. Dai, M. Fan, Carbon 81 (2015) 465-473.

[27] D. Li, T. Ma, R. Zhang, Y. Tian, Y. Qiao, Fuel 139 (2015) 68-70.

[28] A.S. Ello, L.K.C. de Souza, A. Trokourey, M. Jaroniec, Microporous Mesoporous Mater. 180 
(2013) 280-283.

[29] M.G. Rabbani, H.M. El-Kaderi, Chem. Mater. 24 (2012) 1511-1517.

[30] Z. Zhang, K. Wang, J.D. Atkinson, X. Yan, X. Li, M.J. Rood, Z. Yan, J. Hazard. Mater. 229-230 (2012) 183-191.

[31] W. Hao, E. Björkman, M. Lilliestråle, N. Hedin, Applied Energy 112 (2013) 526-532.

[32] W. Cai, L. Tan, J. Yu, M. Jaroniec, X. Liu, B. Cheng, F. Verpoort, Chem. Eng. J. 239 (2014) 207-215.

[33] A. Wahby, J.M. Ramos-Fernández, M. Martínez-Escandell, A. Sepúlveda-Escribano, J. Silvestre-Albero, F. Rodríguez-Reinoso, ChemSusChem 3 (2010) 974-981. 